\title{
High-speed flowing plasmas in the Earth's plasma sheet
}

\author{
FU SuiYan ${ }^{1,2^{*}}$, SHI QuanQi ${ }^{3}$, WANG $\mathrm{Chi}^{3}, \mathrm{PARKS}^{3}$ George ${ }^{4}, \mathrm{ZHENG} \mathrm{Ling}^{1}, \mathrm{ZHENG} \mathrm{Hao}^{1}$ \& \\ SUN WeiJie ${ }^{3}$
}

${ }^{1}$ School of Earth and Space Sciences, Peking University, Beijing 100871, China;

${ }^{2}$ State Key Laboratory of Space Weather, Chinese Academy of Sciences, Beijing 100190, China;

${ }^{3}$ School of Space Science and Physics, Shandong University at Weihai, Weihai 264209, China;

${ }^{4}$ Space Sciences Laboratory, UC Berkeley, Berkeley, CA94720-5200, USA

Received November 11, 2010; accepted December 22, 2010

\begin{abstract}
A research topic of great interest to the space physics community is the observation of plasmas flowing at hundreds of kilometers per second in the Earth's plasma sheet. Although considerable effort has been made to understand the source of fast-flowing plasmas, many questions remain unanswered about the mechanisms that produce high-speed flows and the effects they have on magnetospheric disturbances, especially their contributions to magnetospheric convection and substorms. In this paper, we discuss briefly the history of high-speed flows and review the proposed mechanisms, signatures of high-speed flows in auroras and their interaction with the background plasma. We then summarize the relationships between high-speed flows and magnetic structures, discuss questions associated with substorms, and finally pose several important scientific questions that need to be addressed.
\end{abstract}

plasma sheet, high speed flow, magnetic structure, substorm, dipolarization

Citation: $\quad$ Fu S Y, Shi Q Q, Wang C, et al. High-speed flowing plasmas in the Earth's plasma sheet. Chinese Sci Bull, 2011, 56: 1182-1187, doi: 10.1007/s11434$011-4361-y$

\section{High-speed flowing plasma in the plasma sheet}

The Earth's magnetosphere is formed by the interaction between the solar wind and geomagnetic field. The interconnection of the interplanetary magnetic field (IMF) with the geomagnetic field at the magnetopause and subsequent reconnection on the nightside leads to the formation of a long geomagnetic tail. The plasma sheet is a region of closed field lines inside the magnetotail. An imbalance of the reconnection processes can produce a large amount of energy stored in the tail lobe region. This energy is released when substorms occur with dramatic changes in magnetic structures in the magnetosphere and the acceleration of particles to high energies. High-speed (several hundred $\mathrm{km} / \mathrm{s}$ ) plasma flows are usually observed during these times.

*Corresponding author (email: suiyanfu@ @ku.edu.cn)
Fast-flowing plasma events in the magnetotail were first observed in the plasma sheet boundary layer (PSBL) in the late 1970s [1]. Later, using data from AMPTE/IRM, Baumjohann et al. [2] reported observations of high-speed flows in the inner central plasma sheet (ICPS). The results showed that the occurrence rate of high-speed flows in the ICPS exceeded those in the outer plasma sheet (OPS) and PSBL. The term bursty bulk flow (BBF) was first used by Angelopoulos et al. [3] to describe the high-speed plasma flow events. They found the BBFs in the ICPS were correlated to the auroral electrojet (AE) index and solar wind conditions. According to AMPTE/IRM and ISEE2 data, BBFs in the ICPS mainly occur during active periods of the magnetosphere and have an average duration of $\sim 10$ min $[3,4]$. The data also indicated that the occurrence probability of BBFs increases as the $\mathrm{AE}$ index increases. To date, there is no precise definition of high-speed flows and researchers usually apply their own criteria based on the physical problems they are studying. However, if the bulk speed of protons is 
higher than $300-400 \mathrm{~km} / \mathrm{s}$, it is generally considered as a fast-flow event. The bulk speed is sometimes referred to as the plasma flow speed perpendicular to the local magnetic field direction. Both field-aligned and convective highspeed flows have been studied [5]; however, the convective flows are more important in substorm research. A fast-flow event that lasts longer than $10 \mathrm{~min}$ is called a BBF event, while events with a time scale of a few minutes or tens of seconds are referred to as flow bursts.

It should be noted that the bulk flow speed of the particles is not measured directly but is calculated from the distribution of particle fluxes. Chen [6] reported that if the flow speed of ions is used as the only criterion for high-speed flows, then when the distribution function deviates from the Maxwellian distribution, the effect of integration could yield high speeds even though there is no real bulk flow. In addition, Lee et al. [7] showed that when particles are moving near a boundary, the integration effect could lead to a non-zero speed in some direction. Therefore, the distribution functions must be carefully studied when high-speed flow problems are studied.

\subsection{High-speed flows in magnetic convection and substorms}

High-speed flows are observed in only $10 \%-15 \%$ of the data obtained by satellites traveling through the plasma sheet $[4,8]$. The total energy transported by high-speed flows accounts for about $10 \%$ of energy released by substorms. In addition, observing a high speed-flow event does not necessarily mean there is a substorm in progress $[9,10]$. However, because most of the time the convection speed in the plasma sheet is relatively low $[11,12]$, the general view is that high-speed flows play an important role in plasma convection and studies of high-speed flows have been closely tied to substorm research.

A traditional theory of plasma convection has tried to explain the so-called "pressure catastrophe" issue [13]. When the plasma moves toward the Earth under the influence of the convective electric field, a sufficient amount of magnetic flux must also be transported to account for the dipolarization effect. The scale of the high-speed flows and magnetic flux they transport with them help us estimate the contribution of high-speed flows in the whole convection processes.

It has been reported that high-speed flows are small-scale structures, forming filaments in the plasma sheet [14] (Figure 1). Angelopoulos et al. [15] showed that the scale of a single BBF in the geocentric solar ecliptic (GSE) $Y$ - $Z$ plane is less than $3 \mathrm{R}_{\mathrm{E}}$. Slavin et al. [16] suggested that the scale of BBFs during the substorm expansion phase have scale lengths close to $5-10 \mathrm{R}_{\mathrm{E}}$. On the basis of the velocity gradient observed by Cluster, Nakamura et al. [17] found the average scale of BBFs to be $2-3 \mathrm{R}_{\mathrm{E}}$ in the dawn-dusk direction and $1-2 \mathrm{R}_{\mathrm{E}}$ in the north-south direction.

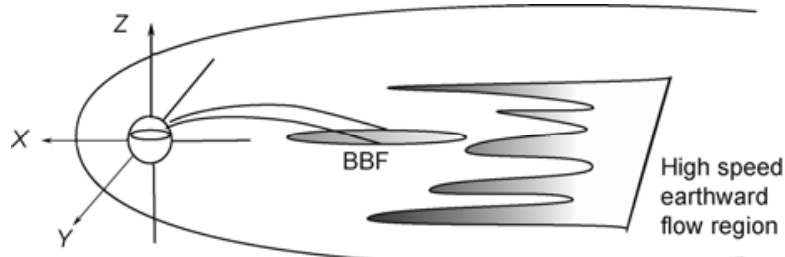

Figure 1 Schematic illustration of high-speed flows in the plasma sheet (after Sergeev et al. [14])

Using multi-satellite observations and comparing the results with those from single-satellite observations, Cao et al. [18] found (with data recorded by three satellites) that the average duration of BBFs is $\sim 18 \mathrm{~min}$, which is longer than the 10 min obtained by single-satellite observations. They also showed that BBFs are not observed in $\sim 4.5 \%$ of substorm events, which is much lower than the $22 \%$ deduced from single-satellite observations. The contribution of highspeed flows to the convective flow from single-satellite observations is very likely to be underestimated.

The earthward flowing high-speed flows can transport a large amount of magnetic flux that could lead to a magnetic field pileup [19-21]. Baumjohann et al. [22] suggested that the dipolarization and the tailward retreat of the dipolarization region are due to the braking of the high-speed flows. From AMPTE/IRM observations, Shiokawa et al. [23] determined the distribution of high-speed flows and showed that the occurrence rate is much lower in the region $13 \mathrm{R}_{\mathrm{E}}<$ $|X|<15 \mathrm{R}_{\mathrm{E}}$, and thus proposed that the current produced by the braking of high-speed flows, which is opposite in direction to the cross-tail current, could lead to current interruption and a substorm onset. However, although the braking of high-speed flows may set up a current system similar to a substorm current wedge, it cannot evidently produce a westward current jet sufficient to produce a real substorm [24]. Recently, Pu et al. [25] proposed that when high-speed flows produced by reconnection in the middle tail reach the near-Earth plasma sheet, they can cause instability leading to current disruption and triggering of the substorm expansion phase.

Because high-speed flows are often observed during substorm activity, many works have focused on their counterparts in the aurora. Fairfield et al. [26] studied the correlation between substorms and high-speed flows at $X>-15 \mathrm{R}_{\mathrm{E}}$. Ieda et al. [27] showed that when GEOTAIL observed a high-speed flow at $X<-20 \mathrm{R}_{\mathrm{E}}$, the footprint of the satellite mapped to a local brightening region of the aurora or north of it. Nakamura et al. [28] suggested that short-lived high-speed flows at $10-30 \mathrm{R}_{\mathrm{E}}$ are closely related to local auroral breakup, and the active aurora can be explained by the current system formed by the velocity shear at the boundary of the flows [29] (Figure 2). Yahnin et al. [30] studied 15 flow-reversal events in the plasma sheet and showed that when the flow changed from tailward to earthward, the corresponding aurora moved poleward of the satellite foot-point. In addition, 


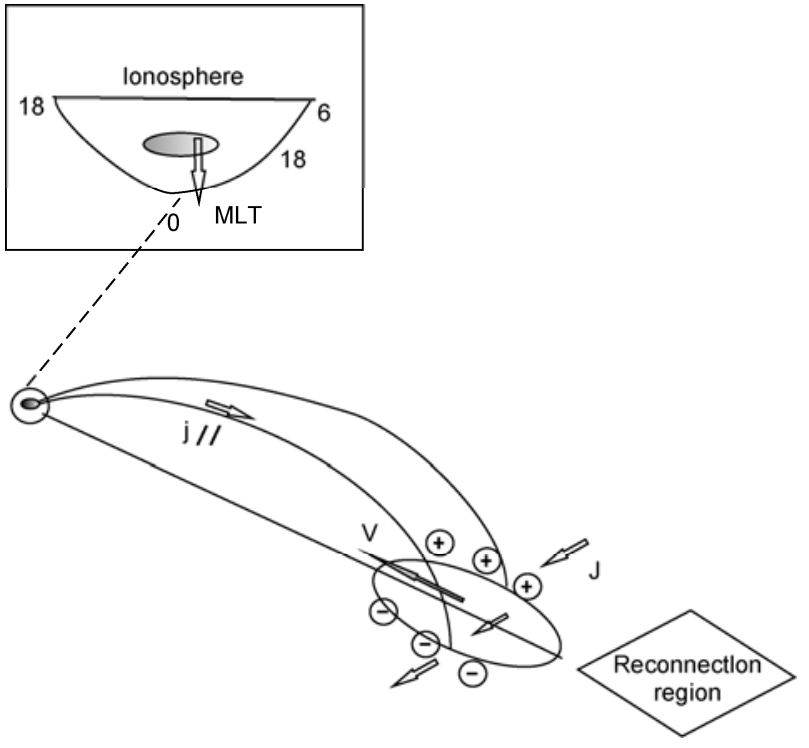

Figure 2 Field-aligned current and auroral signatures related to highspeed flows (after Nakamura et al. [32]).

more and more observations have now shown a close relationship between high-speed flows in the plasma sheet and the north to south streaming auroral structures [31-34].

However, there is still debate about the relationship between flows and auroras. Using POLAR observations, Shue [35] showed that almost half of flow events had weak auroral activity and that high-speed flows can be observed during periods of very low activity. Moreover, the occurrence rate of high-speed flows is not much different for active and quiet conditions [36]. Shue et al. [37] proposed that high-speed flows can be divided into two groups based on the level of auroral activity. He suggested that for high-speed flows at $X=-10 \mathrm{R}_{\mathrm{E}}$, the energy fluxes of aurora change rapidly, showing that this kind of flow event can greatly enhance the nightside auroral intensity, and at the same time, typical auroral substorm signatures can be observed. On the other hand, high-speed flows at $X<-15 \mathrm{R}_{\mathrm{E}}$ will accompany relatively mild variations of the aurora, with obvious poleward expansion and signatures of pseudo-breakups. Some of the flows in this second group will continue to move earthward, causing substorm onsets at later times.

\subsection{Formation of high-speed flows and relation with magnetic structures}

Reconnection is an effective process for transforming magnetic energy into kinetic energy. High-speed flows are often thought to be produced by reconnection in a localized region of the plasma sheet. Using data obtained by AMPTE/IRM and ISEE2, Angelopoulos et al. [4] found that most tailward flows are at around $X=-19 \mathrm{R}_{\mathrm{E}}$. According to the direction and magnetic field signatures associated with high-speed flows observed by Geotail, Nagai et al. [38] concluded that the near-Earth reconnection sites are located in the region $20-30 R_{E}$ in the tail.

There is great debate on whether high-speed flows are produced only by reconnection. Lui et al. [39] suggested that in the current-interruption region, the imbalance can also induce earthward flows. Since dipolarization is observed together with high-speed flows, the flows observed in the near-Earth region could also be thought of as possible dipolarization effects. Earthward flows could also be explained by the theory of the "plasma bubble" proposed by Chen and Wolf [40]. Plasma bubbles are often low-density structures that move earthward under the effects of the polarization electric field.

Early in the 1980s, tailward flowing magnetic structures and plasmoids were studied using ISEE-3 observations, and more research has been done since the launch of Geotail. In the meantime, earthward flowing plasmoids or magnetic structures have also been observed [41,42]. Plasmoids are observed singly or in groups $[41,43]$. Frequently, the observed flux ropes are believed to be evidence of a near-Earth multi-X line reconnection process that can produce more than one plasmoid in the plasma sheet. It is implied that the position of the reconnection site affects the moving direction of the structures [44]. The multi-X line reconnection model has also been supported by multiple flux rope structures observed by Cluster and Double Star [45].

Although much has been learned about magnetic structures and high-speed flows, the relationship between them is still unclear. High-speed flows are thought to be magnetic structures since the plasma parameters are similar for flows and structures [24]. Slavin et al. [41] suggested there is a close relationship between these two and divided the flux rope events into "BBF-type" and "Plasmoid-type" events (Figure 3). They found that flux ropes with a scale of 2-5 $\mathrm{R}_{\mathrm{E}}$ could be observed every 5 hours. Magnetic disturbances are observed immediately after or just inside the flow. About $60 \%$ of the observed structures could be explained by a force-free model. According to their model, the BBF-type structures would have an average scale of $1.4 \mathrm{R}_{\mathrm{E}}$ with a field of $20 \mathrm{nT}$ in the center of the structure, while for plasmoid-type structures, the magnitudes are $4.4 \mathrm{R}_{\mathrm{E}}$ and $14 \mathrm{nT}$. Slavin et al. [41] also analyzed a BBF structure with a scale of $1 \mathrm{R}_{\mathrm{E}}$ and concluded that this structure was not force-free because it had apparently interacted with the background plasma. Tailward flowing structures form plasmoid structures that are often observed in the magnetotail during substorms [46]. There are also other ideas in which the magnetic field variation is thought to be the result of interaction with the background, but not necessarily a part of the magnetic structure or flow.

\subsection{Interaction of high-speed flow with the background plasma}

Observations indicating interactions between high-speed 


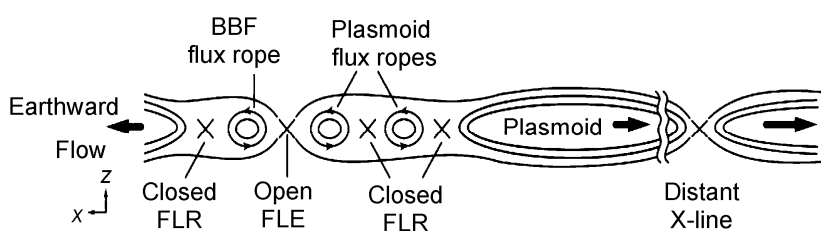

Figure 3 Magnetic structures and high-speed flows in the plasma sheet (from Slavin et al. [44]).

flows and the background plasma have drawn more and more attention recently. These include the observations of reverse flows near the flow flank region, magnetic flux pileups in the near-Earth region and dipolarization processes. It has been reported that the $B_{y}$ component often observed before the high-speed flows is evidence of vortex structures in the flow boundary [47]. High-speed flows are also thought to be the source of some of the large-scale wave-like phenomena observed in the plasma sheet [48].

By carefully comparing tailward and earthward flows, Ohtani et al. [49] showed that earthward flows are often accompanied by magnetic-field dipolarization. He showed that a weaker $B_{z}$ and enhanced number density are observed before dipolarization, while a deceased density and increased temperature are observed at dipolarization. Both the ion pressure and total pressure were observed to decrease during the high-speed flows. For the tailward flows, the changes in plasma parameters are the same but not as rapid as those for the earthward flows. The rapid changes in earthward flows could be a consequence of braking induced by the stronger magnetic field on the earthward side, while such obstacles are not encountered in the tailward flows.

The boundary region formed when the high-speed flows decelerate has strong electric field fluctuations (Figure 4), and the particle energy spectra can differ within the scale of the ion Larmor radius [50]. The formation and transportation of the dipolarization front is a new research topic. Rich wave modes from low-hybrid frequencies to electron gyrofrequencies have been found at the boundaries [51]. It is still unclear if these dipolarization fronts are independent of or related to the braking of high-speed flows.

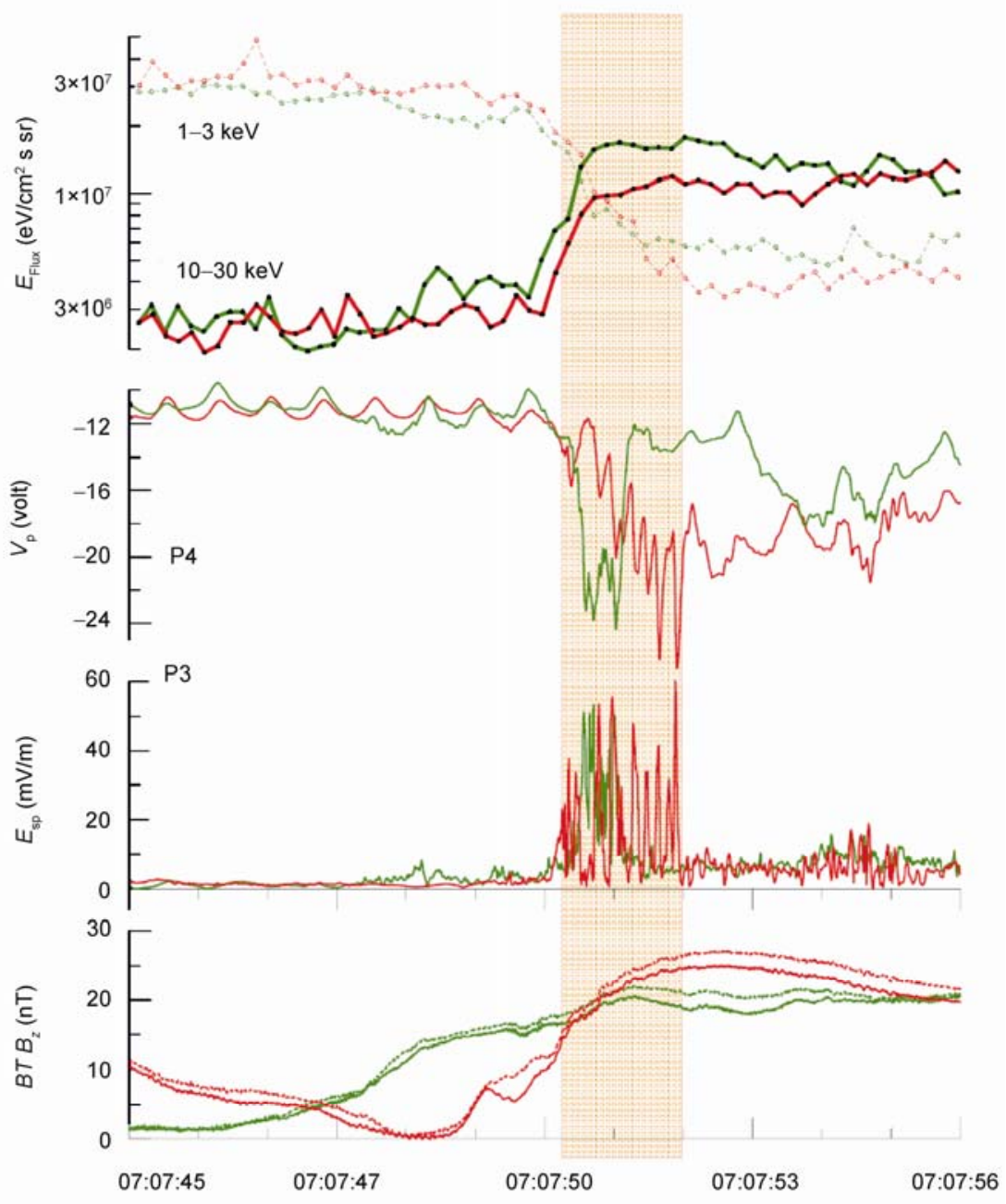

Figure 4 Electric field disturbances observed in front of high-speed flows (from Sergeev et al. [50]). 


\subsection{Ion composition in high-speed flows}

Oxygen ions $\left(\mathrm{O}^{+}\right)$from the Earth's ionosphere can be observed in the plasma sheet during periods of geomagnetic disturbance [52]. Kistler et al. [53] showed that the number density and pressure of $\mathrm{O}^{+}$in the plasma sheet can be five times that measured during non-storm periods. The different behaviors of $\mathrm{O}^{+}$ions and protons are thought to be due to the different dynamical processes they undergo in the reconnection region due to the different gyroradii of the particles. In studies of the energetic particles in flows it has been shown that compared with the background plasma population, earthward high-speed flows have a relatively low ratio of $\mathrm{O}^{+} / \mathrm{H}^{+}$, while the ratio is higher for tailward flows [54]. It is still not known how the results will be different when reconnection occurs in an oxygen-rich plasma sheet. Shay et al. [55] suggested that there will be new scales in the reconnection with three-component plasma including $\mathrm{O}^{+}$ions, namely magnetic disturbances related to "heavy whistlers" and velocity disturbances of the scale corresponding to "heavy Alfvén waves". They predicted that the speed of outflow from the reconnection region could be a factor of 2 slower than that expected based on the reconnection rate with only $\mathrm{H}^{+}$present. According to their theory, the expansion phase of substorms will take longer and less lobe magnetic flux will be reconnected in the same amount of time. These implications of the theory need more observations for verification.

\section{Important scientific problems and summary}

Although high-speed flow events have been observed for more than 20 years, there is still much ongoing research into the formation mechanism and the effects of the events on magnetosphere convection and substorms. More research is needed to better our understanding of the related physics. Important questions to be answered include whether there are other mechanisms that produce high-speed flows in addition to the reconnection mechanism; whether high-speed flows are simply a kind of magnetic structure; how the scale, speed and parameters of plasma flowing toward the Earth evolve in time; how the background plasma affects the high-speed flows; whether the braking effect is the same as near-Earth dipolarization; whether dipolarization is more frequent during strong geomagnetic disturbances and closer to the Earth; whether high-speed flow events have the same auroral signatures as magnetic structures; and what the influence of $\mathrm{O}^{+}$ions is in reconnection and substorm triggering processes.

The apogee of Cluster is about $20 \mathrm{R}_{\mathrm{E}}$, and the four satellites will observe the plasma sheet many times during their lifetime. Four satellites orbiting close together make it feasible to study small-scale structures and their dynamics. With the help of Double star observations, it is possible that a larger-scale picture can also be obtained at the same time. THEMIS was designed to study substorm models with five satellites lined up in the plasma sheet. THEMIS also provides a good opportunity to study the evolution of multiscale high-speed flows and magnetic structures. Moreover, the THEMIS ground-based observatory can provide rich observations of aurora. These observations studied systematically could provide a deeper understanding of the physical process.

This work was supported by the National Natural Science Foundation of China (40874086 and 41031065) and the Specialized Research Fund for State Key Laboratories (08262DAA4S).

1 Lui A T Y, Eastman T E, Williams D J, et al. Observations of ion streaming during substorms. J Geophys Res, 1983, 88: 7753-7764

2 Baumjohann W, Paschmann G, Lühr H. Characteristics of high-speed ion flows in the plasma sheet. J Geophys Res, 1990, 95: 3801-3809

3 Angelopoulos V, Baumjohann W, Kennel C F, et al. Bursty bulk flows in the inner central plasma sheet. J Geophys Res, 1992, 97: 4027-4039

4 Angelopoulos V, Kennel C F, Coroniti F V, et al. Statistical characteristics of bursty bulk flow events. J Geophys Res, 1994, 99: $21257-$ 21280

5 Zhang L Q, Liu Z X, Ma Z W, et al. Convective high-speed flow and field-aligned high-speed flows explored by TC-1. Chinese Sci Bull, 2008, 53: 2371-2375

6 Chen L J, Parks G K, McCarthy M, et al. Kinetic properties of bursty bulk flow events. Geophys Res Lett, 2000, 27: 1847-1850

7 Lee E, Wilber M, Parks G K, et al. Modeling of remote sensing of thin current sheet. Geophys Res Lett, 2004, 31: L21806, doi:10.1029/2004G L020331

8 Angelopoulos V, Mozer F S, Mukai T, et al. On the relationship between bursty flows, current disruption and substorms. Geophys Res Lett, 1999, 26: 2841-2844

9 Lyons L R, Nagai T, Blanchard G T, et al. Association between Geotail plasma flows and auroral poleward boundary intensifications observed by CANOPUS photometers. J Geophys Res, 1999, 104: 44854500

10 Ohtani S, Yamaguchi R, Kawano H, et al. Does the braking of the fast plasma flow trigger a substorm?: A study of the August 14, 1996, event. Geophys Res Lett, 2002, 29: doi: 10.1029/2001G- L013785

11 Huang C Y, Frank L A. A statistical study of the central plasma sheet: Implications for substorm models. Geophys Res Lett, 1986, 13: 652-655

12 Baumjohann W, Paschmann G, Sckopke N, et al. Average ion moments in the plasma sheet boundary layer. J Geophys Res, 1988, 93: 11507-11520

13 Erickson G M, Wolf R A. Is steady convection possible in the Earth's magnetotail? Geophys Res Lett, 1980, 7: 897-900

14 Sergeev VA, Sauvaud J-A, Popescu D, et al. Multiple-spacecraft observation of a narrow transient plasma jet in the Earth's plasma sheet. Geophys Res Lett, 2000, 27: 851-854

15 Angelopoulos V, Phan T D, Larson D E, et al. Magnetotail flow bursts: Association to global magnetospheric circulation, relationship to ionospheric activity,and direct evidence for localization. Geophys Res Lett,1997, 24: 2271-2274

16 Slavin J A, Fairfield D H, Lepping R P, et al. WIND, GEOTAIL, and GOES 9 observations of magnetic field dipolarization and bursty bulk flows in the near-tail. Geophys Res Lett, 1997, 24: 971-974

17 Nakamura R, Baumjohann W, Mouikis C, et al. Spatial scale of high-speed flows in the plasma sheet observed by Cluster. Geophys Res Lett, 2004, 31: L09804, doi:10.1029/2004GL019558

18 Cao J B, Ma Y D, Parks G, et al. Joint observations by Cluster satellites of bursty bulk flows in the magnetotail. J Geophys Res, 2006, 111: A04206, doi:10.1029/2005JA011322 
19 Zhang H, Pu Z Y, Cao X, et al. TC-1 observations of flux pileup and dipolarization-associated expansion in the near-Earth magnetotail during substorms. Geophys Res Lett, 2007, 34: L03104, doi:10.1029/ 2006GL028326

20 Cao X, Pu Z Y, Zhang H, et al. Multi-spacecraft and ground-based observations of substorm timing and activations: Two case studies. J Geophys Res, 2008, 113, doi:10.1029/2007JA012761

21 Cao X, Pu Z Y, Zhang H, et al. Continuous lobe reconnection in the mid-tail and its relationship to substorms: Cluster observations of continuous lobe reconnection in the mid-magneto tail. Chinese Sci Bull, 2005, 50: 2057-2063

22 Baumjohann W, Hesse M, Kokubun S, et al. Substorm dipolarization and recovery. J Geophys Res, 1999, 104: 24995-25000

23 Shiokawa K, Baumjohann W, Haerendel G. Braking of high-speed flows in the near-Earth tail. Geophys Res Lett,1997, 24: 1179-1182

24 Cao J B, Yan C, Dunlop M, et al. Geomagnetic signatures of current wedge produced by fast flows in a plasma sheet. J Geophys Res, 2010, 115: A08205, doi:10.1029/2009JA014891

25 Pu Z Y, Chu X N, Cao X, et al. THEMIS observations of substorms on 26 February 2008 initiated by magnetotail reconnection. J Geophys Res, 2010, 115: A02212, doi:10.1029/ 2009JA014217

26 Fairfield D H, Mukai T, Brittnacher M, et al. Earthward flow bursts in the inner magnetotail and their relation to auroral brightenings, AKR intensifications, geosynchronous particle injections and magnetic activity. J Geophys Res, 1999, 104: 355-370

27 Ieda A, Shue J-H, Liou K, et al. Quiet time magnetotail plasma flow: Coordinated Polar ultraviolet images and Geotail observations. J Geophys Res, 2003, 108, doi:10.1029/2002JA009739

28 Nakamura R, Baumjohann W, Brittnacher M, et al. Flow bursts and auroral activations: Onset timing and foot point location. J Geophys Res, 2001, 106: 10777-10789

29 Birn J, Hesse M. Details of current disruption and diversion in simulations of magnetotail dynamics. J Geophys Res, 1996, 101: 1534515358

30 Yahnin A G, Despirak I V, Lubchich A A, et al. Relationship between substorm auroras and processes in the near-earth magnetotail. Space Sci Rev, 2006, 122: 97-106

31 Nakamura R, Oguti T, Yamamoto T, et al. Equatorward and poleward expansion of the auroras during auroral substorms. J Geophys Res, 1993, 98: 5743-5759

32 Nakamura R, Baumjohann W, Schödel R, et al. Earthward flow bursts, auroral streamers, and small expansions. J Geophys Res, 2001, 106: 10791-107802

33 Amm O, Kauristie K. Ionospheric signatures of bursty bulk flows. Surv Geophys, 2002, 23: 1-32

34 Frey H U, Amm O, Chaston C C, et al. Small and meso-scale properties of a substorm onset auroral arc. J Geophys Res, 2010, 115: A10209, doi:10.1029/2010JA015537

35 Shue J H, Ohtani S, Newell P T, et al. Quantitative relationship between plasmasheet fast flow and nightside auroral power. J Geophys Res, 2003, 108: 1231, doi:10.1029/2002JA009794

36 Ohtani S, Mukai T. Statistical characteristics of storm time plasma sheet. J Geophys Res, 2008, 113: A01221, doi:10.1029/2007JA012547

37 Shue J H, Ieda A, Lui A T Y, et al. Two classes of earthward fast flows in the plasmasheet. J Geophys Res, 2005, 113: A02205, doi:

\subsection{9/ 2007JA012456}

38 Nagai T, Fujimoto M, Saito Y, et al. Structure and dynamics of magnetic reconnection for substorm onsets with Geotail observations. J Geophys Res, 1998, 103: 4419-4440

39 Lui A T Y, Yoon P H, Chang C L. Quasi-linear analysis of ion Weibel instability in the Earth's neutral sheet. J Geophys Res, 1993, 98: 153-163

40 Chen C X, Wolf R A. Interpretation of high-speed flows in the plasma sheet. J Geophys Res, 1993, 98: 21409-21419

41 Slavin J A, Lepping R P, Gjerloev J, et al. Geotail observations of magnetic flux ropes in the plasma sheet. J Geophys Res, 2003, 108: 1015, doi:10.1029/2002JA009557

42 Zong Q-G, Fritz T A, Pu Z Y, et al. Cluster observations of earthward flowing plasmoid in the tail. Geophys Res Lett, 2004, 31: L18803, doi:10.1029/2004GL020692

43 Slavin J A, Smith M F, Mazur E L, et al. ISEE-3 observations of traveling compression regions in the Earth's magnetotail. J Geophys Res, 1993, 98: 15425-15446

44 Slavin J A, Tanskanen E I, Hesse M, et al. Cluster observations of traveling compression regions in the near-tail. J Geophys Res, 2005, 110: A06207, doi:10.1029/2004JA010878

45 Walsh A P, Fazakerley A N, Wilson R J, et al. Near-simultaneous magnetotail flux rope observations with Cluster and Double Star. Ann Geophys, 2007, 25: 1887-1897

46 Hones E W. Substorm processes in the magnetotail: Comments on "On hot tenuous plasma, fireballs, and boundary layers in the Earth's magnetotail” by L.A. Frank et al. J Geophys Res, 1977, 82: 5633-5640

47 Dmitrieva N P. Cross-tail velocity component in the plasma sheet fast flows. Ann Geophys, 2008, 26: 1597-1604

48 Zhang T L, Nakamura R, Volwerk M, et al. Double Star/Cluster Observation of neutral sheet oscillations on 5 August 2004. Ann Geophys, 2005, 23: 2909-2914

49 Ohtani S, Shay M A, Mukai T. Temporal structure of the fast convective flow in the plasma sheet: Comparison between observations and twofluid simulations. J Geophys Res, 2004, 109: A03210, doi:10.1029/2003JA010002

50 Sergeev V, Angelopoulos V, Apatenkov S, et al. Kinetic structure of the sharp injection/dipolarization front in the flow-braking region. Geophys Res Lett, 2009, 36: L21105, doi:10.1029/2009GL040658

51 Zhou M, Ashour-Abdalla M, Deng X H, et al. THEMIS observation of multiple dipolarization fronts and associated wave characteristics in the near-Earth magnetotail. Geophys Res Lett, 2009, 36: L20107, doi:10.1029/2009GL040663

52 Nose M, Ohtani S, Takahashi $\mathrm{K}$, et al. Ion composition of the near-Earth plasma sheet in storm and quiet intervals: Geotail/EPIC measurements. J Geophys Res, 2001,106: 8391-8403

53 Kistler L M, Mouikis C G, Cao X, et al. Ion composition and pressure changes in storm time and nonstorm substorms in the vicinity of the near-Earth neutral line. J Geophys Res, 2006, 111: A11222, doi: 10.1029/2006JA011939

54 Ruan P, Fu S Y, Zong Q G, et al. Ion composition variations in the plasma sheet observed by Cluster/RAPID. Geophys Res Lett, 2005, 32: L01105, doi:10.1029/2004GL021266

55 Shay M A, Swisdak M. Three-Species collisionless reconnection: Effect of $\mathrm{O}^{+}$on magnetotail reconnection. Phys Rev Lett, 2004, 93, doi: 10.1103/PhysRevLett.93.175001

Open Access This article is distributed under the terms of the Creative Commons Attribution License which permits any use, distribution, and reproduction in any medium, provided the original author(s) and source are credited. 